\title{
Reading Developmental Trends in Early Years: The Influence of Word Identification Skills and Target Langauge Oral Ability to Comprehension
}

\author{
Grace Njoki Mwathe \\ Kenya Institute of Curriculum Development, Nairobi, Kenya
}

\begin{abstract}
Language, reading, and reading-related tasks were administered to 148 children from lower primary (Standard 1, 2, and 3) in Kenyan schools. The aim was to investigate the literacy developmental trends across the years and establish which of the two variables, word identification skills or target language oral proficiency influenced reading comprehension performance. The results indicated that word identification skills independently influenced reading comprehension performance in both standard 2 and standard 3 classes, but target language oral skills did not. Further, the analysis of invented spelling task performance revealed evidence of transfer of alphabetic coding skills of first language to English orthography. The spelling errors reflected letter-sound patterns not found in English orthography. Analysis of the miscues in the spelling task revealed that children rely on first language phonological processes to spell target language unfamiliar words as long the languages have a common alphabetic system.
\end{abstract}

Keywords: first language, oral ability, target language, word level skills

Many children in Kenya complete their lower primary (Standard 1, 2, and 3) education with limited literacy skills in English language. According to Uwezo Kenya (2014) annual learning assessment, only 3 out of 10 Standard 3 children can read Standard 2 level English story. Further, 1 out of 6 children in the same Class 3 cannot read an English word. A key objective in the English Course Syllabus (Ministry of Education-Kenya, 2002) states that at the end of the first three years (Standard 1 to 3), the child should have acquired a sufficient command of vocabulary and language patterns to enable him to use English as a medium of learning in upper primary (Standard 4 to 8). In addition, it states that specifically, the child should acquire proficient reading skills in English to enable him/her to read and understand instructions, to read for information and for pleasure.

The question of whether this objective is being realized has been critical particularly with the onset of free primary education since 2002. A number of surveys in Kenya (Piper, 2010, 2012; Uwezo Kenya, 2011, 2012, 2014) have indicated low reading achievement levels. For instance, Piper (2012) found that 30\% of standard 2 pupils could not read a simple English story resulting to extremely low comprehension scores. And the Uwezo Kenya (2012) annual learning assessment report reveals that only half of Class 3 children could read simple Class 2 level paragraphs.

Grace Njoki Mwathe, Chief Curriculum Developer in the Department of Curriculum and Research Services in Kenya Institute of Curriculum Development. 
While a number of factors contribute to low reading achievements, of critical importance is the content as prescribed in the syllabus which tends to focus more on formal language elements and structures than on the specific reading-related strategies. For example, in Standard 1, although naming the letters of the alphabet appears as a key learning activity, it does not feature anywhere in the language content section. Instead, the teaching of formal sentence patterns and structures, and vocabulary development form the main part of language content, an observation that has been made in Nigerian primary schools (Oyetunde, 2002). Similarly in Standard 2, the language content focuses mainly on sentence patterns and structures, vocabulary development (using pictorial dictionaries), and reading sentences using substitution tables and only identifying the sounds of letters in groups (e.g., th, sh) is introduced. In Standard 3, phonics becomes part of the learning activities for reading skills development where children learn letter sounds and spelling patterns through, for example, use of rhymes and tongue twisters. It appears therefore, that the emphasis is initially on development of language skills (using context-related strategies) and the word recognition skills are later introduced gradually.

However, over time studies from second language learners indicate that word recognition skills are crucial in the early stages of reading acquisition (Atwili, Blanchard, Christie, Gorin, \& Garcia, 2010; Durgunoglu, 1998; Geva \& Wade-Woolley, 1998; Tregar \& Wong, 1984; Datta; 2000; Vaughn et al., 2006). Indeed, the cross-linguistic transfer principle (Cummins \& Swains, 1986) suggests that it is the word recognition skills that primarily transfer across languages. For example, statistically significant, strong positive correlations were found between Spanish Initial Sound Fluency (ISF) and English ISF, and between Spanish Phoneme Segmentation Fluency (PSF) and English PSF (Atwili et al., 2010) implying the occurrence of cross language transfer for phonemic awareness. It appears that for target language (L2) literacy development, children need to be provided with an approach that will emphasize word identification skills earlier rather than later.

\section{Word Identification Strategies}

There are several ways to identify a word, with general cognitive maturation level of the individual reader (Juel, 1984) and their prior experience largely influencing the skill or a combination of skills that the reader uses to recognise words. One strategy refers to phonetic-cue reading which involves identifying a word based on features of only a few of its letters (Spear-Swerling \& Sternberg, 1998). Readers may, for example, rely on the first or the final letter only to identify a word. As a result a child might use the letter $c$ to identify the word cat, $g$ to identify the word $d o g$ and $o o$ to identify the word, book. Phonetic-cue reading has its limitations because many similar words may differ by only one letter. For example, a phonetic cue reader might misread the word look as book if the cue is $o o$.

Another way in which words may be recognised is by sight. This involves recognising words as wholes. According to Ehri (1997) the term "sight" indicates that sight of the word activates the word in memory, including information about its spelling, pronunciation, typical role in sentences, and meaning. Readers are also able to use syntactic and semantic redundancies of language to generate hypotheses (i.e., guesses) of what the word is. One major weakness with this strategy, however, concerns the unpredictability of language. Since nearly all sentences are novel, the meaning that is embedded in each sentence must also be novel. Therefore, it is important that all the words in the sentence are read accurately otherwise the intended meaning is likely to be distorted. 
Use of analogies (Bruck \& Treiman, 1992; Goswami, 1999) is another word identification strategy which involves reading a new word by recognising how its spelling is similar to a word already known. Goswami (1999) argues that the relations that a child needs to have represented in order to use analogies in reading are the phonological relations that operate in the language that they are learning to read. Words therefore, may also be identified by phonological recoding process. These processes involve transforming graphemes (written symbols) into phonemes (sound symbols) and blending them into pronunciations that approximate real words. Successful acquisition of phonemic awareness is necessary for children to apply letter-sound correspondence rules in identifying unfamiliar words.

\section{Relation of Word Identification to Comprehension of Text}

Comprehension is a critical factor and main purpose in the reading process. Reading has indeed been characterised as a two-stage process: first word recognition (which is mainly through decoding) and secondly comprehension (Gough \& Tunmer, 1986). Proficient readers, therefore, should identify printed words with ease, effortlessly and automatically, and use their knowledge of spelling-sound correspondences when necessary to figure out unfamiliar words as they actively construct meaning. In support of this argument, Datta (2000) refers to word recognition as lower-order skills and comprehension as higher-order skills, affirming that children have to fully master the lower-order English reading skills first. Pressley (1998) also argues that the inability to decode interferes with strategic functioning above the word level, because use of active comprehension strategies requires a great deal of short-term capacity.

Thus, poor phonological skills lead to less reading, and little opportunity to increase basic vocabulary and knowledge through reading, leaving a shaky foundation for later comprehension (Juel, 1991). It has been recognized that impaired language segmentation skills leads to difficulties in phonological coding which in turn impede the word identification processes which underpin comprehension (Stanovich, 1996). In other words, word identification is likely to be a cause and not a consequence of reading comprehension difficulties. Studies have established that children who are experiencing reading difficulties have their core deficits in phonological skills (Gustafson, Falth, Svensson, Tjus, \& Heimann, 2011; Fuchs et al., 2012; McNamara et al. 2011, SasKatchewan, 2004). Fuchs et al. (2012), for instance, found that phonological processing and Rapid Automatized Naming (RAN) were statistically significant predictors; they are important for explaining reading comprehension as well as reading at the word level.

More importantly, there is evidence demonstrating the generalizability of these findings to the L 2 children. Studies with L2 learners, for instance, have suggested that universal, cognitive and linguistic factors, such as phonological processing, working memory, orthographic knowledge and speed of lexical access are involved in reading skills acquisition for L2 children (Atwili et al., 2010; Birch, 2002; Leafstedt, Richards, \& Gerber, 2004; Limbos \& Geva, 2001; Vaughn et al., 2006). Limbos and Geva (2001), for example, argue that researchers are applying cognitive factors to the assessment and diagnosis of reading difficulties among English L2 learners. Further, Vaughn et al. (2006) found significant differences favouring learners who were provided intervention condition on Spanish measures of letter naming fluency, phonological awareness, letter-sound identification, verbal analogies, word reading and spelling. Furthermore, Atwili et al. (2010) examined the influence of native vocabulary development on cross-language transfer of phonemic awareness and found statistically significant, strong positive correlations between Spanish Initial Sound Fluency (ISF) and English ISF, and between Spanish Phoneme Segmentation Fluency (PSF) and English PSF. 
Rosowsky (2001) tested six bilingual (English-Pakistani) and six monolingual (English) pupils using the Neale Analysis of Reading Ability. The results indicated that the bilinguals performed significantly higher (Average raw score $=52$ ) than monolinguals (Average raw score $=36$ ), in reading accuracy. However, in comprehension, the monolinguals (74) outperformed the bilinguals (55). An analysis of miscues showed that the monolingual pupils used substitutions $65.6 \%$ of the time and mispronunciations $24 \%$ of the time. The bilingual pupils, on the other hand, used substitutions $22.4 \%$ of the time and mispronunciations $71.3 \%$ of the time. This led to the argument that monolingual pupils were using strategies that strove to elicit meaning from the text while the bilingual pupils were using strategies that were more word-based, resulting in more mispronunciations than substitutions.

These studies suggest L2 learners need to master the word recognition skills as a base for proficient reading. This may be particularly critical for L2 learners because they may not have an adequate vocabulary repertoire to engage in substitution or guessing skills when reading for McLaughlin and Allen (2009) states that vocabulary development and instruction affects reading comprehension. Therefore, extensive practice in reading is necessary for L2 children to develop vocabulary, syntactic and semantic awareness, which are necessary but not sufficient for reading comprehension. Therefore the bottom-up and top-down processes are both critical for fluent reading, but low-level (decoding) processes may of necessity, precede higher-level (meaning making) processes in literacy instructional programs.

\section{L2 Oral Proficiency and L2 Reading}

Although there is not a significant research base on oral English-language development for L2 learners (Tong et al., 2008) in multi-lingual contexts, studies investigating the relationship between L2 oral proficiency and L2 reading ability (Geva et al., 1993; Tregar \& Wong, 1984; Verhoeven \& Aarts, 1998) indicate that variables other than oral language proficiency are more powerful predictors of the children's reading task performance in L2. A partial explanation for this finding is that not all children who are orally proficient in a language can read in that language. For example, in a study of the concurrent literacy development of English speaking children who were learning Hebrew as a L2, Geva et al. (1993) found that the children's limited oral proficiency in Hebrew did not adversely affect their Hebrew spelling or decoding, which had been explicitly taught. The children were able to spell and decode at levels beyond their beginning L2 status.

Similarly, Verhoeven and Aarts (1998) with Turkish-English bilinguals, found that a key predictor of bilingual children's reading in the L2 was their ability to transfer knowledge about reading from one language to another, other than L2 oral proficiency. On the other hand, Limbos and Geva (2001) found that L2 oral proficiency contributed to misclassifications of students who have English as a Second Language (ESL). Because of their rudimentary L2 oral skills, ESL student's reading skills were mistakenly assessed as poor. More often ESL students are placed in classes where they are taught vocabulary and oral language skills, with the assumption that this will result in improvement in reading ability, an assumption that is inherent in the Language curriculum in Kenya. However, research has indicated that oral language skills such as vocabulary or grammatical knowledge were either marginally related or not related to word-identification performance (Geva \& Siegel, 2000). Perhaps oral language skills such as oral communication proficiency may not significantly correlate with variables such as letter knowledge and phonemic awareness. Indeed, Geva and colleagues (Geva et al., 1993; Geva \& Wade-Woolley, 1998; Limbos \& Geva, 2001) speculated that the oral proficiency measures used with young L2 children did not capture the types of oral language knowledge and skills that 
predicted their reading in multi-lingual contexts.

It has been found that code switching (orally switching from one language to another) is very common in bi-/multilingual contexts even at classroom level (Setati, Alder, Reed, \& Bapoo, 2002; Young, 2002). Setati et al. (2002) state that the most important aspect of bi-/multilingualism (that which makes the bi-/multilingual person an integrated whole) is code switching, and can therefore be expected to occur in bi-/multilingual classroom communication. Therefore, code-switching should be viewed as learning and teaching resource that provides the support needed while the learners continue to develop proficiency in the language of learning and teaching. In this sense, code switching plays a bridging role between native language and L2. Hence, in early years, L2 children should be provided with instruction that is most beneficial as they move from low oral proficiency to code switching to oral fluency in L2 an inherent aspect of multi-lingual contexts.

The critical issue is that children in multilingual contexts who may be learning a second or a third language (which more often becomes the medium of instruction) are provided with instruction using L1 approaches. The fact that they are learning another language places these children at high risk of reading failure. The problem is compounded by the fact that most of the native languages, especially in Africa, have little or no teaching resources. Since the evidence suggests that instruction in word level strategies is helpful in overcoming these handicaps, the challenge is to change, modify and/or improve the classroom literacy instruction to this effect, the basis of this study.

\section{Objective of the Study}

The main objective of the study was to investigate the literacy developmental trends across the years and establish which of the two variables, word identification skills or target language oral proficiency influenced reading comprehension performance.

\section{Research Questions}

(1) Is there a higher correlation between word recognition skills and reading comprehension than between L2 oral ability and reading comprehension?

(2) To what extent do Kenyan primary school children transfer their first language orthographic literacy skills to second language orthography?

(3) To what extent do children in Kenyan lower primary schools use word-based strategies in identifying difficult or unfamiliar words when reading in English?

\section{Method}

\section{Participants}

The main aim of the study was to determine which of the two variables: target language (L2) oral ability (i.e., language skills) or L2 word recognition skills, would influence L2 reading comprehension, and at what year level. To address this question, a cross-sectional study was adopted. This design was adopted since the study was interested in tracing L2 literacy developmental trends from Standard 1 to Standard 3. A random sample of 148 children was selected from 5 schools in Makueni County.

To assess the reading ability of these children, language, reading, and reading-related tasks were administered to the sample. The assessment tasks used in the current study were designed and adapted from English first language learners. This was based on the fact that studies with bi-/multilingual learners, have 
suggested that universal cognitive and linguistic factors, such as phonological awareness, working memory, orthographic knowledge, and speed of lexical access, are involved in reading skills acquisition for both first language and L2 children (Geva \& Siegel, 2000; Limbos \& Geva, 2001; Vaughn et al., 2006).

Reading tasks given to the children included the Peabody Picture Vocabulary Test (PPVT) which is a measure of language oral ability. Teachers were also asked to rate children according to an English oral language proficiency rating scale that was provided. The rating scale ranged from 1 to 5 where 1 represented those with very low English proficiency, and 5 for those with good command of the language. Other reading-related tasks included the Sound Matching task which was an adaptation of a task developed by Bryant, Bradley, Maclean, and Crossland (1989). This task, which was given to Standard 1 and 2 children, comprised two parts: an onset matching task and a rime-matching task. Context free word identification ability was assessed by a list of words adapted from Ready to Read Word Test (Clay, 1985) and was administered to standard 1 and 2. The Burt Word Reading Test (Gilmore, Croft, \& Read, 1981) was also given to Standard 2 and 3 children to assess context free word identification ability.

An invented spelling task was administered to Standard 2 and 3 children. The children were asked to write the words that were read aloud by the tester, first in a sentence, then in isolation. The 26 letters of the alphabet were displayed across the top of the children's response page to assist with the spelling task.

The accuracy and comprehension subtests of the Neale Analysis of Reading Ability, Revised (Neale, 1988) were administered to Standard 2 and 3 children. This provided measures of accuracy for identifying words in connected text and reading comprehension ability. The children read aloud a series of short stories that were graded in difficulty. Children's comprehension was tested by asking them to answer some comprehension questions.

\section{Children's Reported Word Identification Strategy Task}

Information about the children's word identification strategies was obtained by asking each child the following question: "When you are reading on your own and come across a word that you don't know, what do you do to try and figure out what the word is?" The children's responses were coded according to whether reference was made to the use of word-based strategies, or text-based strategies. Examples of word-level strategies included "go through all the letters, name the alphabets loudly, sound the letters in the word". Examples of text-based strategies were "try to guess", "have a look at the picture", "ignore and read on", and "try to remember the word". Non-responses to this question were also noted.

\section{Results and Discussion}

Language, reading, and reading-related tasks in English language were administered to 148 children. The aim was to investigate the pattern of relationships among the language and reading measures in each class, and the developmental trends in reading acquisition across the years. It was predicted that word identification measures would consistently influence reading comprehension performance more than the oral language ability in all the years.

\section{Concurrent Correlations}

Presented in Tables 1, 2, and 3 are the intercorrelations, means, and standard deviations for measures taken in Standard 1, Standard 2, and Standard 3, respectively. In Standard 1 both letter identification and word identification correlated significantly with oral language, suggesting that knowledge of the language of 
instruction is helpful in learning to identify letters and words. Only letter identification correlated significantly with receptive vocabulary. As might be expected, letter identification and sound matching each correlated

significantly with word identification, although the magnitude of the latter correlation (0.25) was low, perhaps because instruction at this stage focuses mostly on learning frequently occurring words as whole word visual patterns (i.e., Sight words) as indicated in the syllabus. Phonological sensitivity (as measured by sound matching in Standard 1) would be expected to play a greater role when children begin employing more analytical approaches in identifying words. Overall, the magnitudes of the significant correlations among Standard 1 measures tended to be rather weak, most likely because performance on some of the measures (most notably word identification) approached floor levels.

Table 1

Intercorrelations, Means, and Standard Deviations for Standard 1 Measures

\begin{tabular}{|c|c|c|c|c|c|}
\hline Measures & 1 & 2 & 3 & 4 & 5 \\
\hline 1. Oral language & & 0.12 & $0.37^{* * *}$ & 0.03 & $0.38^{* *}$ \\
\hline 2. Receptive vocabulary (PPVT) & & & $0.37^{* *}$ & 0.16 & 0.18 \\
\hline 3. Letter identification & & & & 0.20 & $0.43^{* *}$ \\
\hline 4. Sound matching & & & & & $0.25^{*}$ \\
\hline \multicolumn{6}{|l|}{ 5. Word identification } \\
\hline$\underline{\mathrm{M}}$ & 2.18 & 37.9 & 45.4 & 12.5 & 6.7 \\
\hline$\underline{\mathrm{SD}}$ & 0.85 & 6.9 & 8.8 & 3.3 & 5.9 \\
\hline Maximum Score & 5.00 & 175.0 & 54.0 & 18.0 & 45.0 \\
\hline
\end{tabular}

Notes. $N=50 .{ }^{*} p<0.05,{ }^{* *} p<0.01$.

In Standard 2 all correlations were significant except that between oral language and context free word identification. A possible reason for why receptive vocabulary correlated significantly with context free word identification, whereas oral language did not, is that general knowledge of the meanings of words may be particularly helpful in making holistic associations between the spoken and the written form of words. As expected the ability to detect sound sequences in spoken words (as measured by sound matching) correlated more highly with the ability to use mapping between subcomponents of written and spoken words (i.e., preconventional spelling) than it did with other measures. In turn, the alphabetic coding measure (preconventional spelling) correlated more highly with the word identification measures than did the other reading-related measures. Finally, both the alphabetic coding and word identification measures correlated more highly with reading comprehension than did the measures of oral language development (i.e., oral language and receptive vocabulary). The latter finding is consistent with the claim that word identification skills are relatively more important than oral language skills during early stages of learning to read.

For Standard 3 measures, all correlations were significant. As had occurred in Standard 2, ability to detect sound sequences (which was measured by a different measure of phonological sensitivity in Standard 3, namely, phoneme segmentation) correlated more highly with the alphabetic coding measure (preconventional spelling) than it did with any of the other measures. The alphabetic coding and word identification measures again correlated highly with reading comprehension, but not as highly as they did in Standard 2. However, the opposite pattern was observed with the measures of language ability (oral language, receptive vocabulary). Both measures correlated more highly with reading comprehension in Standard 3 than they did in Standard 2. These results are similar to those reported by Hoover and Gough (1990), where developmental changes were 
found in the relative contributions of word identification skills and oral language proficiency to variance in reading comprehension, with word identification/alphabetic coding skills accounting for more of the variance in the lower classes and oral language ability for more of the variance in the upper classes. Oral language ability appears to become more important at somewhat later stages of learning to read after children have begun to develop fluency in word recognition, and when children's reading materials have become more advanced in components of language that are common to both oral language and reading comprehension (i.e., semantics, syntax, pragmatics).

Table 2

Intercorrelations, Means, and Standard Deviations for Standard 2 Measures

\begin{tabular}{|c|c|c|c|c|c|c|c|c|}
\hline Measures & 1 & 2 & 3 & 4 & 5 & 6 & 7 & 8 \\
\hline 1. Oral language & & $0.49^{* * *}$ & $0.42^{* * *}$ & 0.16 & $0.39^{* *}$ & $0.41^{* *}$ & $0.28^{*}$ & $0.26^{*}$ \\
\hline 2. Receptive vocabulary (PPVT) & & & $0.27^{*}$ & $0.48^{* *}$ & $0.39^{* *}$ & $0.61^{* * *}$ & $0.41^{* *}$ & $0.34^{* *}$ \\
\hline 3. Sound matching & & & & $0.38^{* *}$ & $0.48^{* *}$ & $0.62^{* *}$ & $0.46^{* *}$ & $0.36^{* *}$ \\
\hline 4. Word identification (Clay) & & & & & $0.64^{* *}$ & $0.68^{* *}$ & $0.73^{* *}$ & $0.69^{* *}$ \\
\hline 5. Word identification (Burt) & & & & & & $0.75^{* * *}$ & $0.77^{* *}$ & $0.77^{* *}$ \\
\hline 6. Preconventional spelling & & & & & & & $0.75^{* *}$ & $0.67^{* *}$ \\
\hline 7. Neale Reading Accuracy & & & & & & & & $0.93^{* *}$ \\
\hline \multicolumn{9}{|l|}{ 8. Neale Reading comprehension } \\
\hline$\underline{\mathrm{M}}$ & 2.38 & 50.6 & 15.0 & 27.9 & 24.5 & 39.6 & 14.2 & 2.6 \\
\hline$\underline{\mathrm{SD}}$ & 0.78 & 9.2 & 3.3 & 13.3 & 13.6 & 13.4 & 7.4 & 2.2 \\
\hline Maximum score & 5.00 & 175.0 & 18.0 & 45.0 & 110.0 & 72.0 & 100.0 & 44 \\
\hline
\end{tabular}

Notes. $N=50 .{ }^{*} p<0.05,{ }^{* *} p<0.01$.

Table 3

Intercorrelations, Means, and Standard Deviations for Standard 3 Measures

\begin{tabular}{|c|c|c|c|c|c|c|c|}
\hline Measures & 1 & 2 & 3 & 4 & 5 & 6 & 7 \\
\hline 1. Oral language & & $0.44^{* * *}$ & $0.60^{* *}$ & $0.67^{* *}$ & $0.47^{* * *}$ & $0.44^{\text {*** }}$ & $0.45^{* * *}$ \\
\hline 2. Receptive vocabulary (PPVT) & & & $0.62^{* *}$ & $0.46^{* *}$ & $0.39^{* *}$ & $0.52^{* *}$ & $0.42^{* *}$ \\
\hline 3. Phoneme segmentation & & & & $0.66^{* *}$ & $0.72^{* *}$ & $0.63^{* *}$ & $0.58^{* *}$ \\
\hline 4. Word identification (Burt) & & & & & $0.57^{* *}$ & $0.67^{* *}$ & $0.70^{* *}$ \\
\hline 5. Preconventional spelling & & & & & & $0.62^{* * *}$ & $0.64^{* *}$ \\
\hline 6. Neale Reading Accuracy & & & & & & & $0.94^{* *}$ \\
\hline \multicolumn{8}{|l|}{ 7. Neale Reading Comprehension } \\
\hline$\underline{\mathrm{M}}$ & 2.73 & 58.3 & 14.3 & 37.4 & 49.0 & 22.8 & 5.2 \\
\hline$\underline{\mathrm{SD}}$ & 0.84 & 10.3 & 3.5 & 11.5 & 10.5 & 9.2 & 2.8 \\
\hline Maximum score & 5 & 175 & 24 & 110 & 72 & 100 & 44 \\
\hline
\end{tabular}

Notes. $N=48 .^{*} p<0.05,{ }^{* *} p<0.01$.

\section{Developmental Trends}

The results presented in Table 4 show significant differences between the means for each measure that was administered in two or more classes. As expected, the children in higher classes significantly outperformed the children in lower classes on all reading and reading-related measures. However, the developmental trends for the language measures were rather weak, especially that for oral language, where individual comparisons of cell means revealed a significant difference between Standard 1 and 3 only (Scheffe, $p<0.05$ ). An analysis of individual scores on the oral language rating scale revealed that 19 of the 48 children in Standard 3 received a 
rating of 2 or below. Earlier research has shown that there is a monotonically increasing, parabolic relationship between oral language proficiency and reading achievement, suggesting that children must attain a threshold level of competence in the language being read before they can achieve substantial progress in reading comprehension performance (Tunmer \& Hoover, 1992). Approximately 40\% of the Standard 3 children appear to be below this threshold level of competence in English, and probably more.

Table 4

One-way Analyses of Variance of MEASUres Taken Across Standard Levels

\begin{tabular}{|c|c|c|c|c|c|c|c|c|}
\hline \multirow[t]{2}{*}{ Measure } & \multicolumn{2}{|c|}{$\begin{array}{l}\text { Standard } 1 \\
(N=50)\end{array}$} & \multicolumn{2}{|c|}{$\begin{array}{c}\text { Standard } 2 \\
(N=50)\end{array}$} & \multicolumn{2}{|c|}{$\begin{array}{c}\text { Standard } 3 \\
(N=48)\end{array}$} & \multicolumn{2}{|c|}{ ANOVA } \\
\hline & $\underline{\mathrm{M}}$ & $\underline{\mathrm{SD}}$ & $\underline{\mathrm{M}}$ & $\underline{\mathrm{SD}}$ & $\underline{\mathrm{M}}$ & $\underline{\mathrm{SD}}$ & $\underline{\mathrm{df}}$ & $\underline{F}$ \\
\hline Oral language & 2.18 & 0.85 & 2.38 & 0.78 & 2.73 & 0.84 & 2.145 & $5.54^{*}$ \\
\hline Receptive vocabulary & 37.88 & 6.88 & 50.58 & 9.23 & 58.33 & 10.30 & 2.145 & $66.24^{* *}$ \\
\hline Sound matching & 12.48 & 3.30 & 15.00 & 3.27 & - & - & 1.98 & $14.73^{* *}$ \\
\hline Word identification (Clay) & 6.68 & 5.87 & 27.86 & 13.29 & - & - & 1.98 & $106.22^{* *}$ \\
\hline Word identification (Burt) & - & - & 24.48 & 13.58 & 37.44 & 11.55 & 1.96 & $25.79^{* *}$ \\
\hline Preconventional spelling & - & - & 39.60 & 13.44 & 48.96 & 10.47 & 1.96 & $14.70^{* *}$ \\
\hline Neale Reading Accuracy & - & - & 14.20 & 7.39 & 22.81 & 9.21 & 1.96 & $26.16^{* *}$ \\
\hline Neale Reading Comprehension & - & - & 2.62 & 2.17 & 5.17 & 2.82 & 1.96 & $25.23^{* *}$ \\
\hline
\end{tabular}

Notes. ${ }^{*} p<0.01,{ }^{* *} p<0.001$

Table 5

Spelling Miscues that Depicted Cross-language Transfer for Standard 2 and Standard 3

\begin{tabular}{|c|c|c|c|c|}
\hline & & dard & & dard 3 \\
\hline & $N$ & $\%$ & $N$ & $\%$ \\
\hline & 15 & 30 & 9 & 18.75 \\
\hline Target word & mis & & mis & \\
\hline Fat & fati & & fati & \\
\hline Fill & fili & & filli & \\
\hline Pop & & & pop & \\
\hline Bank & ban & & & \\
\hline Side & said & & sadi & \\
\hline Meat & mit, & & mit, & \\
\hline Kick & kiki & & kiki & \\
\hline Hot & Hot & & & \\
\hline Pack & pak & & pak & \\
\hline Van & & & van & \\
\hline Duck & dak & & & \\
\hline Jail jili & & & & \\
\hline Cake & kek & & kek & \\
\hline Tight & tait, & & taiti & \\
\hline
\end{tabular}

A likely explanation for why the Standard 3 children performed reasonably well on the measures of context free word identification (i.e., the Burt test) is that in addition to having received reading instruction in English from school entry, the children received concurrent instruction in two other languages (Kiswahili, which is the national language, Akamba, which is the native language), both of which use alphabetic orthographies that have many of the same letter-sound patterns as English orthography. This would explain 
why the children's alphabetic coding and word identification skills are more advanced than their reading comprehension skills (in English).

Evidence of transfer of alphabetic coding skills from other languages to English orthography comes from spelling errors that reflect letter-sound patterns not found in English orthography. Analysis of the miscues in the spelling task revealed that some children had predictable errors that were mainly additions of vowels at the end of the words, based on their Kiswahili or Akamba phonemic and orthographic knowledge. A word like fill, for example, was spelt as fili, and the word bank had spelling error patterns such as banka, banki, or baniki (see Table 5). This is consistent with the findings from Fashola, Drum, Mayer, and Kang (1996) suggesting that children learning to spell in a L2 would temporarily rely on L1 phonological and orthographic processes to spell L2 words with unfamiliar phonemes and graphemes. Approximately, 30\% of Standard 2 and 18\% of standard 3 children had these typical cross-language errors. Therefore, a further prediction would probably be that if children are concurrently exposed to two or more alphabetic orthographies, more children in lower classes would rely on the orthographic knowledge that they process first (mostly a L1 shallow orthography) to spell, and perhaps to read, unfamiliar L2 words, than higher classes, since differentiation of orthographies would occur at increasing year levels.

Table 6

Frequency and Percentage for Each Response Category of Reported Word Identification Strategies as a Function of Standard Level

\begin{tabular}{|c|c|c|c|c|c|c|}
\hline \multirow{2}{*}{ Response category } & \multicolumn{2}{|c|}{ Standard 1} & \multicolumn{2}{|c|}{ Standard 2} & \multicolumn{2}{|c|}{ Standard 3} \\
\hline & $N$ & $\%$ & $N$ & $\%$ & $N$ & $\%$ \\
\hline Word-based strategies & 7 & 14.0 & 23 & 46.0 & 27 & 56.2 \\
\hline Text-based strategies & 38 & 76.0 & 24 & 48.0 & 20 & 41.7 \\
\hline No response & $\underline{5}$ & $\underline{10.0}$ & $\underline{3}$ & 6.0 & 1 & 2.1 \\
\hline Total & 50 & 100.0 & 50 & 100.0 & 48 & 100.0 \\
\hline
\end{tabular}

\section{Reported Word Identification Strategies}

Presented in Table 6 are the frequency and percentages for each response category of reported word identification strategies as a function of standard level. In first standard most of the children reported relying on text-based strategies (such as using picture cues) to identify unfamiliar words in text. However, at increasing year levels there was a clear shift towards using word-based strategies (such as sounding out letters of the alphabet), a shift that may in part reflect a change in the instructional emphasis in Standard 2 and 3 from using holistic strategies to more analytical strategies (Ministry of Education-Kenya, 2002). In Standard 2, for example, the learning activities for reading skills included identifying sounds of letters and sounds of groups of letters, vocabulary development through using scrap picture books and pictorial dictionaries, and reading sentences from substitution tables. And by Standard 3, children were encouraged to practice new words using phonics and context. This means that there was more emphasis on analytical approaches instruction in Standard 3 than in lower years, where emphasis was more on reading pictorial books and charts, compiling and reading scrap picture books to learn the names of the letters of the alphabet.

Table 7 presents the means, standard deviations and $t$-tests for the language and literacy measures as a function of reported word identification strategy and year level (children who provided no response to the question concerning their preferred word identification strategy were excluded from the analysis). Similar to a study by Vaughn et al. (2006), the children who used word-based strategies generally outperformed the 
children who used text-based strategies on all phonological processing and literacy measures, but not the language measures. The pattern was particularly strong in Standard 2, but less so in Standard 3, perhaps because the children's slow growth in English oral language efficiency was beginning to delay progress in reading despite the fact that the children appeared to have satisfactory word-level skills and tended to prefer using word-based strategies.

Table 7

Means, Standard Deviations, and t-tests for Language and Literacy Measures by Word Identification Strategy Group and Standard Level

\begin{tabular}{|c|c|c|c|c|c|c|c|c|}
\hline \multirow[t]{2}{*}{ Measures } & \multicolumn{3}{|c|}{$\begin{array}{c}\text { Word-based } \\
\text { Strategies Group }\end{array}$} & \multicolumn{3}{|c|}{$\begin{array}{c}\text { Text-based } \\
\text { Strategies Group } \\
\end{array}$} & \multicolumn{2}{|c|}{$t$-test } \\
\hline & $N$ & $M$ & $S D$ & $N$ & $M$ & $S D$ & $d f$ & $t$ \\
\hline \multicolumn{9}{|l|}{ Standard 1} \\
\hline Oral language & 7 & 2.86 & 0.90 & 38 & 2.08 & 0.78 & 43 & $2.36^{*}$ \\
\hline Receptive vocabulary & 7 & 38.14 & 8.82 & 38 & 38.39 & 6.49 & 43 & 0.09 \\
\hline Letter identification & 7 & 50.00 & 1.41 & 38 & 44.26 & 9.68 & 43 & $3.46^{* * *}$ \\
\hline Sound matching & 7 & 14.71 & 3.59 & 38 & 11.95 & 3.26 & 43 & $2.03^{*}$ \\
\hline Word identification (Clay) & 7 & 12.14 & 6.44 & 38 & 6.34 & 5.39 & 43 & $2.54^{*}$ \\
\hline \multicolumn{9}{|l|}{ Standard 2} \\
\hline Oral language & 23 & 2.48 & 0.73 & 24 & 2.38 & 0.82 & 45 & 0.45 \\
\hline Receptive vocabulary & 23 & 53.30 & 7.77 & 24 & 49.33 & 9.31 & 45 & 1.58 \\
\hline Sound matching & 23 & 16.22 & 2.54 & 24 & 14.54 & 3.04 & 45 & $2.05^{*}$ \\
\hline Word identification (Clay) & 23 & 34.83 & 9.04 & 24 & 22.96 & 13.91 & 45 & $3.48^{* * *}$ \\
\hline Word identification (Burt) & 23 & 33.91 & 10.30 & 24 & 17.25 & 10.67 & 45 & $5.44^{* * *}$ \\
\hline Letter-sound knowledge & 23 & 69.48 & 22.49 & 24 & 34.54 & 25.33 & 45 & $4.99^{* * *}$ \\
\hline Preconventional spelling & 23 & 48.52 & 7.81 & 24 & 33.67 & 11.34 & 45 & $5.21^{* * *}$ \\
\hline Neale Reading Accuracy & 23 & 18.57 & 5.23 & 24 & 11.08 & 7.02 & 45 & $4.16^{* * *}$ \\
\hline Neale Reading Comprehension & 23 & 3.78 & 1.88 & 24 & 1.75 & 1.98 & 45 & $3.60^{* * * *}$ \\
\hline \multicolumn{9}{|l|}{ Standard 3} \\
\hline Oral language & 27 & 2.93 & 0.82 & 20 & 2.55 & 0.76 & 45 & 1.59 \\
\hline Receptive vocabulary & 27 & 60.48 & 9.49 & 20 & 56.45 & 10.34 & 45 & 1.39 \\
\hline Phoneme segmentation & 27 & 15.48 & 2.68 & 20 & 13.35 & 3.13 & 45 & $2.51^{*}$ \\
\hline Word identification (Burt) & 27 & 41.19 & 11.43 & 20 & 33.30 & 9.75 & 45 & $2.49^{*}$ \\
\hline Letter-sound knowledge & 27 & 88.48 & 11.23 & 20 & 81.00 & 12.74 & 45 & $2.13^{*}$ \\
\hline Preconventional spelling & 27 & 51.00 & 8.33 & 20 & 48.55 & 7.37 & 45 & 1.05 \\
\hline Neale Reading Accuracy & 27 & 23.81 & 8.61 & 20 & 22.20 & 9.75 & 45 & 0.60 \\
\hline Neale Reading Comprehension & 27 & 5.33 & 2.73 & 20 & 5.15 & 2.91 & 45 & 0.22 \\
\hline
\end{tabular}

Notes. ${ }^{*} p<0.05,{ }^{* *} p<0.01,{ }^{* * *} p<0.001$.

Table 8

Standardized Beta Weights for Regression Equations With Language Factor Score and Word Identification as Predictor Variables and Reading Comprehension as the Criterion Variable for Standard 2 and 3

\begin{tabular}{lll}
\hline Predictor variable & Beta Weights & \\
\cline { 2 - 3 } & Standard 2 & Standard 3 \\
\hline Language factor score & 0.01 & 0.07 \\
Word identification & $0.77^{*}$ & $0.66^{*}$ \\
\hline
\end{tabular}

Note. ${ }^{*} p<0.001$. 


\section{Path Analysis}

To investigate further the relative contribution of word identification skill and oral language proficiency to variance in reading comprehension, path analyses of Standard 2 and 3 data were carried out. Presented in Table 8 are the standardized beta weights for regression equations with language factor score (combining oral language and receptive vocabulary) and word identification (as measured by the Burt test) as predictor variables and reading comprehension as the criterion variable for Standard 2 and 3. The language factor score for oral language and receptive vocabulary accounted for $71.9 \%$ of the variance, and the factor loading for each measure was 0.85. At both year levels word identification made a strong, independent contribution to variance in reading comprehension but the language factor score did not independently influence reading comprehension performance. This finding suggests that word identification skills play a more important role than language skills in acquisition of reading comprehension skills in early years. The results are similar to a study by Limbos and Geva (2001) where L2 oral ability failed to significantly influence the L2 reading comprehension in elementary grades, but did so in middle grades. On the other hand, word identification was found to significantly influence L2 reading comprehension more in lower grades than in higher grades.

\section{Summary and Conclusions}

The main objectives of the study were to: (1) trace the literacy developmental trends from Standard 1 to 3; (2) determine which of the two variables, word identification skills and L2 oral ability would strongly influence L2 reading comprehension; (3) to establish whether children used their L1 orthography to spell L2 unfamiliar words. To investigate these aims, language, literacy and literacy-related tasks were administered to the children in Standard 1, Standard 2, and Standard 3.

Results from the language, literacy and literacy-related measures indicated several findings. First, there was a stronger relationship between word identification skills and reading comprehension in Standard 2 than in Standard 3, but the opposite pattern was observed with measures of language ability. This finding suggested that oral language ability becomes important at somewhat later stages of learning to read after children have begun to develop fluency in word recognition. This finding is consistent with a study by Tong et al. (2008) which found that students consistently demonstrated significant positive linear growth in their oral English development irrespective of program type. Hence word identification skills would account for more of the variance to reading comprehension in the lower than in the upper years of primary schooling.

Further, children in upper classes significantly outperformed children in lower years on all reading and reading-related measures. The developmental trends for language measures were, however, weak, with a significant difference only between Standard 1 and 2 oral language measures. This suggested that a number of children appeared to be below a threshold level of competence that has been found to be critical if children are to achieve sustainable progress in reading comprehension performance in the language being read (Tunmer \& Hoover, 1992).

However, Standard 3 word identification and phonological processing measures were advanced owing perhaps to the evidence of transfer of alphabetic coding skills from other languages (i.e., Kiswahili or Akamba) to English orthography. The influence of L1 orthography to reading and spelling in L2 has been reported in other studies (Durgunoglu, 1998; Atwili et al., 2010). 
Further, results from children's reported word identification strategies' task showed that, at increasing standard levels, there was a clear shift towards using word-based strategies. This shift may partially be due to a change in instructional emphasis in Standard 2 and Standard 3 from using holistic strategies to more analytical strategies (Ministry of Education, 2002). Of importance, similar to findings by Vaughn et al. (2006) the children who used word-based strategies generally outperformed those who used text-based strategies on all phonological processing and literacy measures. The pattern was rather weak in Standard 3, suggesting that the children's slow growth in English oral language ability was probably delaying progress in reading achievement for Tong et al. (2008) considered oral proficiency as one of the most critical components of academic language.

Because of this low L2 oral ability, path analyses showing the relative contribution of oral language proficiency and word identification skill, for both Standard 2 and Standard 3, revealed that language measures failed to make an independent significant contribution to variance in reading comprehension for both year levels. However, word identification skills made a strong independent contribution to variance in reading comprehension at both Standard 2 and 3, suggesting that word identification skills appear to play a more important role than language skills in acquisition of reading comprehension skills, in early years.

\section{Implications for Educational Practice}

According to this study, word-level skills should be introduced earlier rather than later, a position that is at variance with literacy curriculum. This will facilitate the children's word recognition skills, which are necessary but not sufficient for comprehending the text. Proficient readers are those who identify printed words efficiently and automatically since the inability to recognise words automatically interferes with strategic functioning above the word level, because use of active comprehension strategies requires a great deal of short-tem capacity (Pressley, 1998). Perhaps the children in this study were functioning only at word level even after nearly three years of schooling because word recognition skills were introduced later rather than earlier. In fact, it was word identification skills and not language measures that made a significant independent contribution to variance in reading comprehension at both Standard 2 and Standard 3. This means that there is need also for greater focus on L2 oral development, which has been found to depend in part on word recognition ability. This implies that, for L2 children, word recognition skills are the foundation upon which language measures and meaning construction processes develop, and it is therefore necessary that these skills be introduced earlier if these children are to become skilful readers.

\section{Limitations of the Study}

A major weakness with this study may relate to the use of a cross-sectional design. A criticism with this design is that, at each class level, children may have different learning experiences such that the children in Standard 3 may have had different learning experiences when they were in Standard 1 and 2 than what the current Standard 1 and 2 children were experiencing. The study was based on the assumption that, since the English national curriculum is centralised, children at each standard level received similar instruction.

Another criticism of the current study is that it did not investigate the language reading and reading-related performances of children in the other languages (i.e., Kiswahili and Akamba). Other studies (e.g., Atwili et al., 2010) have established that there is a relationship between children's word identification skills in L1 and word identification skills in L2. However, the analysis of spelling miscues revealed that children in this study used their L1 orthography to spell some L2 words. 
A further related problem associated with cross-language transfer, is the failure of this study to investigate home-based literacy experiences a critical factor to Uwezo Kenya (2012) household surveys.

\section{Suggestions for Further Research}

The study adopted a cross-sectional design due to the time constraints. Future research may adopt a longitudinal study to investigate reading developmental trends of the same sample for the three elementary years.

The research focused on English language since it is the language of education in Kenya. Future replications may include other languages to establish whether children can read in their own native languages, and the extent to which native language influences L2 reading development.

The children involved in this study were in lower primary classes (Standard 1 to Standard 3). Future research may include upper primary children, in order to establish the stage at which children differentiate orthographies and stop making cross-language spelling errors.

\section{References}

Atwili, K., Blanchard, J., Christie, J., Gorin, J. S., \& Garcia, H. S. (2010). English-language learners: Implications of limited vocabulary for cross language transfer of phonemic awareness with kindergarteners. Journal of Hispanic Higher Education, 9(2), 104-129.

Birch, B. M. (2002). English L2 reading: Getting to the bottom. Mahwah, NJ: Lawrence Erlbaum Associates.

Bruck, M., \& Treiman, R. (1992). Learning to pronounce words: The limitations of analogies. Reading Research Quarterly, 27, 373-389.

Bryant, P. E., Bradley, L., McClean, M., \& Crossland, J. (1989). Nursery rhymes, phonological skills and reading. Journal of Child Language, 16, 407.

Clay, M. (1985). The early detection of reading difficulties (3rd ed.). Auckland: Heinneman.

Cummins, J., \& Swain, M. (1986). Bilingualism in education. New York: Longman.

Datta, M. (2000). Bilinguality and literacy: Principles and practice. Language Awareness, 10(4), 301-303.

Durgunoglu, A. Y. (1998). Acquiring literacy in English and Spanish in the United States. In A. Y. Durgunoglu, \& L. Verhoeven (Eds.), Literacy development in a multilingual context: Cross-cultural perspectives (pp. 135-146). Mahwah, NJ: Lawrence Erlbaum Associates.

Ehri, L. C. (1997). Sight word learning in normal readers and dyslexics. In B. Blackman (Ed.), Foundations of reading acquisition and dyslexia: Implications for early intervention (pp. 163-189). Mahwah, NJ: Lawrence Erlbaum Associates.

Fashola, O. S., Drum, P. A., Mayer, R. E., \& Kang, S. (1996). A cognitive theory of orthographic transitioning: Predictable errors in how Spanish-speaking children spell English words. American Educational Research Journal, 33(4), 825-843.

Fuchs, D., Compton, D. L., Fuchs, L. S., Brayant, V. J., Hamlett, C. L., \& Lambert, W. (2012). First-grade cognitive abilities as long-term predictors of reading comprehension and disability status. Journal of Learning Disabilities, 45(3), $217-231$.

Geva, E., \& Siegel, L. S. (2000). Orthographic and cognitive factors in the concurrent development of basic reading skills in two languages. Reading and Writing: An Interdisciplinary Journal, 12, 1-30.

Geva, E., \& Wade-Woolley, L. (1998). Component processes in becoming English-Hebrew biliterate. In A. Y. Durgunoglu, \& L. Verhoeven (Eds.), Literacy development in a multilingual context: Cross-cultural perspectives (pp. 85-110). Mahwah, NJ: Lawrence Erlbaum Associates.

Geva, E., Wade-Woolley, L., \& Shany, M. (1993). The concurrent development of spelling and decoding in different orthographies. Journal of Reading Behaviour, 25, 383-406.

Gilmore, A., Croft, C., \& Reid, N. (1981). Burt word reading test, New Zealand (Revised Ed.). New Zealand Council of Educational Research, Wellington, NZ.

Goswami, U. (1999). Phonological development and reading by analogy: Epilinguistic and metalinguistic issues. In J. Oakhill, \& R. Beard (Eds.), Reading development and the teaching of reading (pp.174-200).

Gough, P. B., \&Tunmer, W. E. (1986). Decoding, reading and reading disability. Remedial and Special Education, 7, 6-10. 
Gustafson, S., Falth, L., Svensson, I., Tjus, T., \& Heimann, M. (2011). The effects of three interventions on the reading skills of children with reading disabilities in grade 2. Journal of Learning Disabilities, 44(2), 123-135.

Juel, C. (1984). An evolving model of reading acquisition. In J. A. Niles (Ed), Changing perspectives on research in reading/language processing and instruction (pp. 294-297). Rochester, New York: National Reading Conference.

Juel, C. (1991). Beginning reading. In R. Barr, M. Kamil, P. Mosenthal, \& P. D. Pearson (Eds.), Handbook of reading research (II) (pp. 759-788). New York: Longman.

Leafsteadt, J. M., Richards, C. R., \& Gerber, M. M. (2004). Effectiveness of explicit phonological-awareness instruction for at-risk English learners. Learning Disabilities Research \& Practice, 19(4), 225-238.

Limbos, M. M., \& Geva, E. (2001). Accuracy of teacher assessments of second-language students at risk for reading disability. Journal of learning disabilities, 34(2), 136-160.

Manis, F., Lindsey, K., \& Bailey, C. (2004). Development of reading in grades K-2 in Spanish-speaking English-language learners. Learning Disabilities Research \& Practice, 19(4), 214-224.

McLaughlin, M., \& Allen, M. B. (2009). Guided comprehension in grades 3-8. Newark: International Reading Association.

McNamara, J. K., Scissons, M., \& Gutknecth, N. (2011). A longitudinal study of kindergarten children at risk for reading disabilities: The poor are getting poorer. Journal of learning disabilities, 44(5), 421-430.

Ministry of Education (Kenya). (2002). National English course syllabus. Nairobi: Kenya Institute of Education.

Neale, M. D. (1988). Neale analysis of reading ability (Revised Ed.). Hawthorne, Australia: Australian Council of Educational Research.

Oyetunde, T. O. (2002). Second language reading: Insights from Nigerian primary schools. The Reading Teacher, 55(8), $748-761$.

Piper, B. (2010). Kenya Early Grade Reading Assessment. Findings Snapshot.

Piper, B. (2012). The teaching and learning of reading in Kenya. A PRIMR project briefing note.

Pressley, M. (1998). Reading instruction that works: The case for balanced teaching. New York: Guildford Press.

Rosowsky, A. (2001). Decoding as a cultural practice and its effects on the reading process of bilingual pupils. Language and Education: An International Journal, 15(1), 56-70.

Saskatchewan Learning. (2004). Teaching students with reading difficulties and disabilities: A guide for educators. S. K. Author.

Setati, M., Adler, J., Reed, Y., \& Bapoo, A. (2002). Incomplete journeys: Code switching and other language practices in mathematics, science \& English language classrooms in South Africa. Language and Education: An International Journal, 16(3), 212-233.

Spear-Swerling, L., \& Sternberg, R. J. (1998). Off track: When poor readers become learning disabled. Colorado: Westview Press.

Stanovich, K. E. (1996). Toward a more inclusive definition of dyslexia. Dyslexia, 2, 154-166.

Tong, F., Lara-Alecio, R., Irby, B. J., Mathes, P., \& Kwok, O. (2008). Accelerating early academic oral English development in transitional bilingual and structured English immersion programs. American Educational Research Journal, 45, 1011-1044.

Tregar, B., \& Wong, B. F. (1984). The relationship between native and second language reading comprehension and second language oral ability. In C. Rivera (Ed.), Placement procedures in bilingual education: Education and policy issues (pp. 152-164). Clevedon: Multilingual Matters.

Tunmer, W. E., \& Hoover, W. (1992). Cognitive and linguistic factors in learning to read. In P. Gough, L. Erhi, \& R. Treiman (Eds.), Reading acquisition (pp.175-214). Hillsdale, NJ: Lawrence Erlbaum Associates.

Uwezo Kenya. (2011). Are our children learning? Annual Leaning Assessment Report. Nairobi.

Uwezo Kenya. (2012). Are our children learning? Annual Leaning Assessment Report. Nairobi.

Uwezo Kenya. (2014). Are our children learning? Annual Leaning Assessment Report. Twaweza: East Africa.

Vaughn, S., Cirino, P. T., Linan-Thompson, S., Mathes, P. G., Carlson, C. D., Hagan, E. C., ... Francis, D. J. (2006). Effectiveness of Spanish intervention and an English intervention for English-Language learners at-risk for readingproblems. American Educational Research Journal, 43(3), 449-487.

Verhoeven, L., \& Aarts, R. (1998). Attaining functional biliteracy in the Netherlands. In A. Y. Durgunoglu, \& L. Verhoeven (Eds.), Literacy development in a multilingual context: Cross-cultural perspectives (pp. 111-134). Mahwah, NJ: Lawrence Erlbaum Associates.

Young, C. (2002). First language first: Literacy education for the future in a multilingual Phillipine society. International Journal of Bilingual Education and Bilingualism, 5(4), 221-231. 